\begin{tabular}{|l|l|}
\hline Asian Journal of Pharmaceutical Research \\
and Development
\end{tabular}

Open $\odot$ Access

Available Online at www.ajprd.com

Review Article

\title{
MEASURING AWARENESS OF OVER THE COUNTER ANALGESICS USE AND RISKS ASSOCIATED WITH IT AMONG JORDANIAN POPULATION IN AMMAN
}

\author{
Ali AL-Samydai , Lena A. Al-Elaime, Sundos H. Abbadi, Lubna Al- Khareisha \\ Department of Pharmaceutical Sciences, School of Pharmacy, University of Jordan, Amman, Jordan
}

\begin{abstract}
This is an observational cross-sectional study that examines the awareness of Jordanian consumers regarding the potential risks associated with over-the-counter (OTC) use of paracetamol and non-steroidal anti-inflammatory drugs (NSAIDs) and the effect of family and friends' advice on the use of analgesics, in order to better understand patterns of usage of these products. A questionnaire survey was conducted in Amman (capital). 150 questionnaires were correctly filled then analyzed. The inclusion criteria were Jordanian residents age over18 years and the willingness to participate in the study. The study results showed that the Jordanian population in Amman is familiar with the most important information regarding the risks associated with the use of Analgesics and that they aware of their responsibility of checking medical information before sharing and that is a positive sign.

Keywords: Over the Counter, Analgesics, Awareness, Amman
\end{abstract}

Article Info: Received: 16 Sept, 2018; Review Completed: 29 Sept, 2018; Accepted: 10 Oct, 2018; Available online; 20 Oct 2018

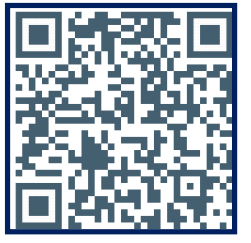

Cite this article as:

Ali AL-Samydai, Lena A. Al-Elaime, Sundos H. Abbadi, Lubna Al-Khareisha, Measuring Awareness of Over the Counter Analgesics Use and Risks Associated With It Among Jordanian Population In Amman,Asian Journal of Pharmaceutical research and Development. 2018; 6 (5):9-15

DOI: http://dx.doi.org/10.22270/ajprd.v6i5.429

*Address for Correspondence:

Lena A. Al-Elaime, Department of Pharmaceutical Sciences, School of Pharmacy, University of Jordan, Amman, Jordan

\section{INTRODUCTION}

\section{Actions of analgesics}

$\mathrm{I}$ $\mathrm{n}$ the midst of the rising healthcare costs around the world, self medication has become an important option in the management of common conditions. Self medication encourages consumers to take an active role in their health. Self medication also provides positive economical outcomes at the societal level. However, the benefits of such self medication practices depend upon their being used responsibly. ${ }^{1}$ Today over-the-counter (OTC) analgesics represent one of the prominent self medication categories. Analgesics are pain-relieving medications normally known as painkillers or pain relievers, are substances which work in various ways to relieve different types of pain experienced in the body. [2] Over-the-counter (OTC) (non-prescribed) analgesics that are generally used by the public are paracetamol, and non-steroidal anti-inflammatory drugs (NSAIDs) such as ibuprofen. $^{3}$

Paracetamol

Paracetamol is (also known as Acetaminophen) is an antipyretic, non-opioid analgesic, and non-steroidal anti- inflammatory drug (NSAID), and is one of most commonly used medications worldwide with nonprescription sales OTC. ${ }^{4}$

Paracetamol is used for mild pain and as an anti-pyretic drug. The mechanism of action of paracetamol is not clearly known, although one theory suggests that it acts as a selective inhibitor of the cyclo-oxygenase enzyme is form, COX-3, found in the brain and spinal cord. Update on its analgesic mechanism of action its analgesic effect was often considered as based on the mobilization of the cyclo-oxygenases and more recently on serotonergic pathways. A new metabolic pathway involving the generation of an active metabolite, AM404 (N-(4Hydroxyphenyl)-5Z,8Z,11Z,14Z-eicosatetraenamide), in the brain by the fatty acid amide hydrolase (FAAH) enzyme, was recently identified. ${ }^{5}$

\section{Non-steroidal anti-inflammatory drugs}

Inhibition of cyclo-oxygenase enzyme-2 (COX-2), which is induced in inflammatory cells, represents the most likely mechanism of action for NSAID-mediated pain relief. However, There is increasing evidence that 
NSAIDs exert their effect not only through inhibition of prostaglandin synthesis peripherally, but also have a central mechanism of action that boosts the peripheral mechanism. This effect may be as a result of either the interference with the production of prostaglandins within the central nervous system or the blockade of serotonin release (5-hydroxytryptamine; 5 -HT) ${ }^{6}$

\section{Aspirin}

The most commonly used over-the-counter NSAID is aspirin (alone or as combination with other compounds). The most common reason for use is the prevention of myocardial infarction or stroke, followed by the relief of all forms of pain. ${ }^{7}$

\section{Ibuprofen}

Ibuprofen was developed directly as a result of the side effects associated with the use of corticosteroids in the treatment of rheumatoid arthritis in addition to the gastrointestinal irritation and general problems of the previously established NSAIDs. Ibuprofen was generally accepted because its therapeutic efficacy was seen to outweigh its side-effects. Ibuprofen was, at the time, the first drug with the potency of aspirin but without its main disadvantages. ${ }^{8}$

\section{Prescription, Dosage and Side effect of Analgesic Medication}

Acetaminophen, aspirin, and ibuprofen are among the most frequently used OTC analgesics, When utilized as recommended, these analgesics are relatively effective, safe, and economical medications for mild to moderate pain and fever. Nevertheless, because of OTC analgesics accessibility and presumed safety, they are among the most commonly taken drugs in overdoses. ${ }^{9}$

Although NSAIDs are efficacious and have a wide margin of safety, they have potentially serious side effects even when taken in appropriate manner. The most common side effect is gastrointestinal irritation due to the inhibition of prostaglandin synthesis in the stomach mucosa which can lead to inflammation and ulceration. Most likely because of its little affinity for COX in that environment, Acetaminophen does not cause gastric irritation. Elderly patients are at higher risk of developing GI adverse effects. Thus, close monitoring of the amount of OTC NSAID ingested is necessary in the management of elderly patients. To minimize GI adverse events, proton-pump inhibitors (PPIs) may be useful as prophylaxis for patients who require NSAIDs for therapy and are at risk for increased GI complications. ${ }^{9,10}$

It is not known whether the patterns of use are consistent with good pain management practices. A better understanding of patterns of use is needed to determine if these patterns are consistent with good pain management practices, the extent of the misuse of OTC analgesics, and whether health outcomes could be improved by public education about the appropriate use of these drugs. ${ }^{11}$

\section{Effect of family and friends}

Available data clearly suggest that social relationships have the potential for both health improving and health damaging effects in adults, and that there are biological pathways for these effects. Such evidence suggests that different sides of the social environment can play a crucial role in future health promotion efforts for older adults, although careful consideration of the potentially positive as well as negative social effects is needed. ${ }^{12}$

\section{PREVIOUS STUDIE}

Self-medication practice (SMP) is the use of medication without the prescription of health care professionals. People may practice self-medication for a variety of reasons, like the urge for self-care, sympathy for family members in sickness, lack of health services, poverty, ignorance, misbelief, and excessive advertisements of drugs 13

A study done in India in two phases showed that the prevalence of self-medication practices among students was $74.6 \%$ and $69.4 \%$, respectively. Oral antibacterial and anti-inflammatory agents and antipyretics were the most common group of drugs used in both phases of the study. ${ }^{14}$ Other study which examined the prevalence of self-medication, on students in Belgrade, Serbia; showed that Self-medication was reported by $79.9 \%$ students. The most frequently self-prescribed medications were analgesics $(55.4 \%){ }^{15}$

Because of high prevalence of Analgesics usage, several studies was conducted to assess side effects and the awareness regarding its use, for example, "Telephone survey" was developed and evaluates the attitudes of 302 adults toward analgesic use and related side effects. Over half $(68 \%)$ reported prior experience with 2 or more side effects. Vomiting (34\%), confusion (32\%), and nausea $(17 \%)$ were ranked as the worst side effects. ${ }^{16}$ Other study in hospitals of Bangladesh which is entitled by "A Survey on Knowledge and attitude about analgesic use and its indication and possible side effects showed that only $27.04 \%$ participants have health science background in education and only 55\% patients get information from doctor about side effects. ${ }^{17}$ A study about patient knowledge of the paracetamol content of over-the-counter (OTC) analgesics showed that patient knowledge of paracetamol-containing products and of the maximum daily dose is currently insufficient to ensure safe use of the drug. ${ }^{18}$

Other study about Drug safety awareness in New Zealand: public knowledge and preferred sources of information showed that Word of mouth was more frequently reported by women than men as a preferred channel for drug safety information (29\% and 14\%, respectively). They said that it is useful to hear about other people's experiences of medications. ${ }^{19}$

These studies showed that the prevalence of selfmedication is high especially the use of Analgesics and the knowledge about its use and side effects is insufficient, therefore strengthening communities awareness on drug side effects and integrated efforts of individuals, communities, health facilities are highly necessary. Despite the negative consequences of Analgesics usage and its high spread, studies on this study area are limited. Therefore, the aim of this study was to assess the awareness of the Jordanian population in Amman regarding the use of Analgesics, its associated benefits and harms, in order to better understand how consumers are using these products. 


\section{Methodology}

A cross-sectional observational study was conducted in Amman city the capital of Jordan. The research team developed a questionnaire that aims at assessing different aspects of Jordanian population awareness regarding the risks associated with the use of analgesics. The questionnaire consisted of four dimensions; the first dimension: the awareness regarding the proper use; the second: The trust in information received from others about analgesics; the third: the awareness regarding side effects associated with the use of analgesics; the fourth: awareness of the Jordanian population in Amman regarding the risks associated with the use of analgesics. The sampling frame was defined as any resident in Jordan above 18 years old. 150 questionnaires were distributed and re-collected from the subjects of the study after explaining the procedure and aim of the study for them. Finally, all data were entered and analyzed using the SPSS software (version 25.0; SPSS, Inc, Chicago, IL).

\section{Study Model}

The study model design was based on study issues, goals, and similar previous literatures ${ }^{20-25}$.

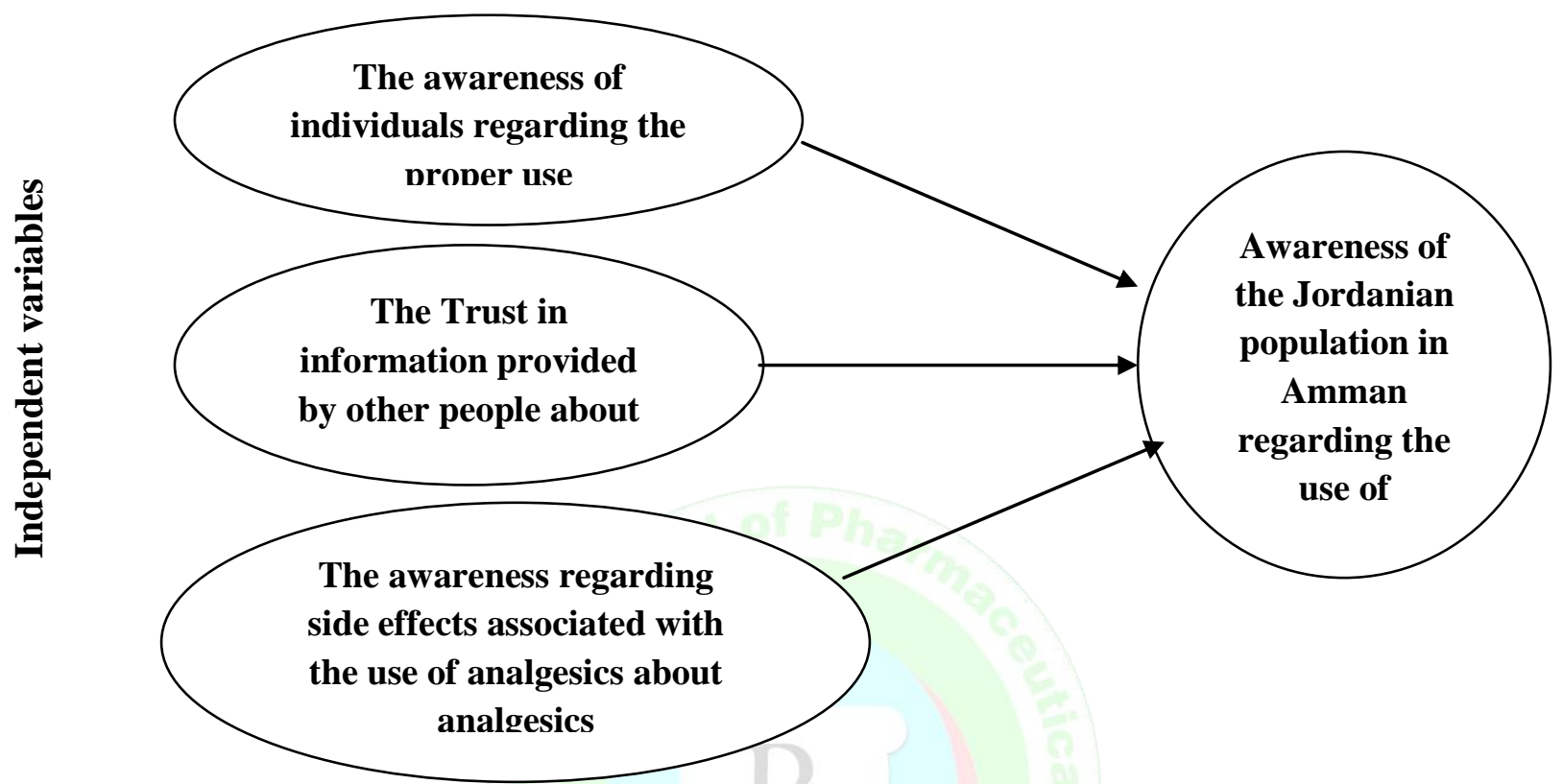

Table 1: Reliability Coefficient

\begin{tabular}{lll}
\hline $\begin{array}{l}\text { No. } \\
\text { Cases }\end{array}$ & $\begin{array}{l}\text { Cronbach's } \\
\text { Alpha }\end{array}$ & No. of Items \\
\hline $\mathbf{1 5 0}$ & .767 & 34 \\
\hline
\end{tabular}

\section{RESULTS}

\section{Test of Reliability}

A reliability coefficient of (Cron boach's Alpha) 70\% or higher is considered "acceptable in most social science research. The result of this test in the current study is $76.6 \%$ as table (1)

\section{General results}

By using descriptive analysis it was determined that all of the questions are over the midpoint (3) except for the questions $(4,6,7,8,9,10,13$, and 20) table (2).

Results indicate that, ranked first with an average of (3.773), individuals in Amman, Jordan think that they understand the medical instructions of analgesics. The ranked last, with an average (1.8133), this indicates that the Jordanian individuals in Amman do not have chronic illness that requires daily use of analgesics.

Testing Hypothesis:

The first category:

Test results of the three hypothesis of the study are shown in Table (3), statistical analysis of this table illustrates the overall mean score of respondent which measures the dimensions (D1, D2, D3, and D4) that correspond to the hypothesis. The mean values of these are $(\mathrm{H} 1=2.76444$ $\mathrm{H} 2=3.1905, \mathrm{H} 3=3.2944, \mathrm{H} 4=3.4422) . \mathrm{H} 2, \mathrm{H} 3$, and H4values are above the scale midpoint (3) with the standard deviation showing small dispersion this mean moreover. These results were further validated by one sample t-test which revealed that the overall mean difference for these dimensions as a whole was statistically significant $(\mathrm{N}=0.000)$ at $(\mathrm{Ns}=0.05)$ with height T. Value, $(\mathrm{H} 1=75.148, \mathrm{H} 2=73.754, \mathrm{H} 3=55.58$, $\mathrm{H} 4=64.049$ ), these scores of the hypothesis (H1, H2, H3, and $\mathrm{H} 4)$ are bigger than tabular $(\mathrm{t}=1.96)$ and sig were (0.000). As a result of, we reject the null hypothesis (People don't have enough awareness about the risks associated with the use of analgesics) and accept the alternative hypothesis according to results shown in the Table (3). 
Table 2: Descriptive statistics and one sample t-test

\begin{tabular}{|c|c|c|c|c|c|}
\hline S.NO & QUESTIONS & Mean & Std. Dev & T Value & Sig. \\
\hline \multicolumn{6}{|c|}{ First dimension: The awareness of individuals regarding the proper use } \\
\hline & & & 1.20 & 32.13 & .000 \\
\hline 2 & You think you know the right amount of analgesic to use to relieve pain. & 3.48 & 0.98 & 43.21 & .000 \\
\hline 3 & $\begin{array}{l}\text { You think you know the biggest dose of } \\
\text { Analgesia. }\end{array}$ & 3.08 & 1.15 & 32.80 & .000 \\
\hline 4 & Use More than one type of analgesics to relieve pain at the same time. & 2.38 & 1.24 & 23.54 & .000 \\
\hline 5 & You use Analgesics without referring to the pharmacist or the physician. & 3.407 & 1.10 & 37.73 & .000 \\
\hline 6 & You think that analgesics are always safe for the person & 2.60 & 0.92 & 34.35 & .000 \\
\hline 7 & You think you can use the analgesics on open number of times a day. & 2.06 & 0.98 & 25.62 & .000 \\
\hline 8 & You think you can never do without analgesics. & 2.87 & 1.06 & 33.08 & .000 \\
\hline 9 & You have a chronic illness requires you to use daily analgesics. & 1.81 & 1.08 & 20.39 & .000 \\
\hline
\end{tabular}

\section{Second Dimension: The Trust in information provided by other people about analgesics}

\begin{tabular}{|c|c|c|c|c|c|}
\hline 10 & $\begin{array}{l}\text { You think you have enough knowledge of how to use different types of } \\
\text { analgesics }\end{array}$ & 2.60 & 1.12 & 28.34 & .000 \\
\hline 11 & Sharing information you already know with other people & 3.41 & 1.06 & 39.09 & .000 \\
\hline 12 & Trust the information that people tell about analgesics & 2.42 & 1.07 & 27.54 & .000 \\
\hline 13 & $\begin{array}{l}\text { Take advice about analgesics from other } \\
\text { people }\end{array}$ & 2.90 & 1.08 & 32.72 & .000 \\
\hline 14 & Trust your family members regarding the use of analgesics & 3.63 & 1.08 & 41.08 & .000 \\
\hline 15 & Check the information you have before sharing it with others & 3.72 & 1.09 & 41.78 & .000 \\
\hline 16 & Check the information you receive from others before you work & 3.64 & 1.116 & 39.84 & .000 \\
\hline
\end{tabular}

Third Dimension: the awareness regarding side effects associated with the use of analgesics

17 Know what are the side effects of
analgesics

\begin{tabular}{|c|c|c|c|c|c|}
\hline 18 & Know the harm defects of analgesics on your health & 3.54 & .98708 & 44.00 & .000 \\
\hline 19 & Know that chronic used of analgesics leads to addiction & 3.59 & 1.13 & 38.75 & .000 \\
\hline
\end{tabular}

$\begin{array}{llllll}\mathbf{2 0} & \text { Know the Drug interactions of analgesics } & 2.68 & 1.23 & 26.70 & .000 \\ \mathbf{2 1} & \text { Know the effect of analgesics on pregnancy and lactation } & 3.15 & 1.24 & 31.12 & .000 \\ \mathbf{2 2} & \text { Know natural alternatives of analgesics } & 3.34 & 1.09 & 37.46 & .000\end{array}$

Fourth Dimension: awareness of the Jordanian population in Amman regarding the use of Analgesics.

\begin{tabular}{llllll}
23 & understand the medical instructions of analgesics & 3.77 & 0.93 & 49.42 & .000 \\
24 & $\begin{array}{l}\text { You think that information from other people about analgesics is important for } \\
\text { you }\end{array}$ & 3.31 & 1.03 & 39.37 & .000 \\
& You think you have knowledge of the side effects of analgesics. & 3.24 & 1.04 & 37.89 & .00 \\
\hline
\end{tabular}


Table 3: Testing Hypothesis

\begin{tabular}{|c|c|c|c|c|}
\hline Hypothesis & Mean & Std. Dev & $\begin{array}{l}\text { T- } \\
\text { value }\end{array}$ & Sig \\
\hline $\begin{array}{l}\text { H1: There is an effect of the awareness regarding the proper use on the } \\
\text { awareness of the Jordanian population in Amman regarding the risks } \\
\text { associated with the use of analgesics }\end{array}$ & 2.76 & .45 & 75.14 & .000 \\
\hline $\begin{array}{l}\text { H2: There is an effect of the Trust in information provided by other } \\
\text { people about Analgesics on the awareness of the Jordanian population in } \\
\text { Amman regarding the risks associated with the use of analgesics. }\end{array}$ & 3.19 & .52 & 73.75 & .000 \\
\hline $\begin{array}{l}\text { H3: There is an effect of the Knowledge of side effects of Analgesics on } \\
\text { the awareness of the Jordanian population in Amman regarding the risks } \\
\text { associated with the use of analgesics. }\end{array}$ & 3.29 & .72 & 55.58 & .000 \\
\hline $\begin{array}{l}\text { H4: There is awareness between the Jordanian population in Amman } \\
\text { regarding the risks associated with the use of analgesics. }\end{array}$ & 3.44 & .65 & 64.04 & .000 \\
\hline
\end{tabular}

\section{The Second Category:}

It tests the construct of the study model. In order to test the relationship between the constructs of the study model and the dependent dimension (D4), Pearson correlation coefficient was adopted and hypothesis (H4) was developed. There is a relationship between the (the awareness of the Jordanian population in Amman regarding the risks associated with the use of analgesics and the awareness regarding the proper use, The trust in information received from others about analgesics and the awareness regarding side effects associated with the use of analgesics), results of the analysis of Pearson's coefficient are shown in the table (4)

Table: 4 Correlations

\begin{tabular}{llllll}
\hline & & D4 & D1 & D2 & D3 \\
\hline Pearson & D4 & 1.000 & .170 & .218 & .419 \\
Correlation & D1 & .170 & 1.000 & .409 & .203 \\
& D2 & .218 & .409 & 1.000 & .196 \\
& D3 & .419 & .203 & .196 & 1.000 \\
\hline
\end{tabular}

Table 4 showed that There were a positive Pearson's correlation between dimension four and each of D1, D2 and D3 and D3 showed strongest positive correlation with D4. So we can conclude that the knowledge in the side effect of Analgesics help in building the awareness of Jordanian population in Amman regarding the risks associated with the use of analgesics.

Table: 5 Model Summary

\begin{tabular}{llllll}
\hline Model & \multirow{R}{*}{} & \multicolumn{4}{l}{ Change Statistics } \\
\cline { 3 - 6 } & & R Square & $\mathrm{F}$ & R Square & $\mathrm{F}$ \\
\multirow{2}{1}{} & $.443^{\mathrm{a}}$ & .196 & 11.890 & .196 & 11.890 \\
\hline
\end{tabular}

Table 5 showed that we concluded that multiple linear regression have been proven to be valid, the results were supported by value of (f) which was calculated to be (11.89), which is greater than the $\mathrm{F}$ table which was (2.604), the value of the statistical significant (Sig.) which was calculated (0.000) is lower than the significant level of (alpha $=0.05$ ), so we reject the null hypothesis (People don't have enough awareness about the risk associated with the usage of analgesic) and accept the alternative hypothesis.

Additionally, determinant Coefficient (R Square) which was calculated as (0.196) showed the elements within the model in general and explained (19.5\%) of the changes that impact awareness about the risks associated with the use of analgesics. Also the regression showed a positive correlation with R $(0.443)$.

\section{Normal Distribution:}

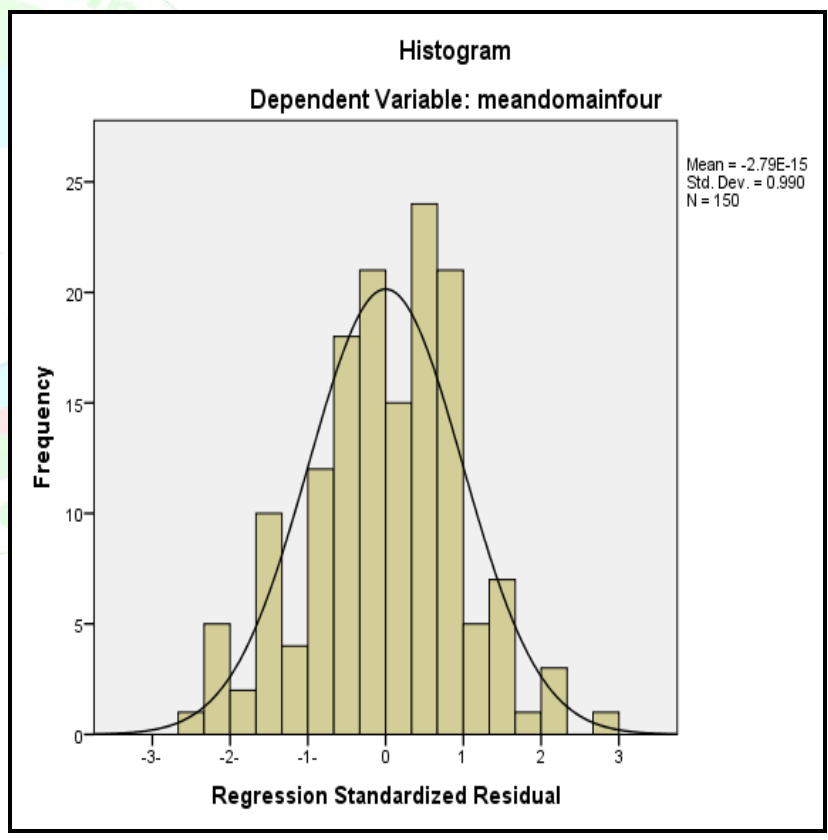

Figure 1: Showed the results of normal distribution values for variable data:

Figure 1 showed that the data presented is adequate to the normal distribution histogram; the skewed distribution is asymmetrical because the natural limit prevents outcomes on one side. The distribution peak is off center towards the limit and a tail starches away from it. Distribution frequency is just above (20); because the results cannot be more than 100 percent pure.

\section{DISCUSSIONS AND CONCLUSIONS}

This study seeks to measure the awareness of the Jordanian population in Amman regarding the risks associated with the use of analgesics. For this purpose a 
model of study has been developed, which includes many of factors that have been divided into four dimensions.

- The awareness regarding the proper use, The trust in information received from others about analgesics, The awareness regarding side effects of analgesics, and the awareness of the Jordanian population in Amman regarding the risks associated with the use of analgesics.

- The analysis of the data was mainly based on conducting "Descriptive statistics" to extract the means and the standard deviations. This was followed by one sample T-test analysis to examine the hypothesis. In order to test the relationship between the constructs of the study model and the dependent dimension (D4), Pearson correlation coefficient was adopted.

- The important results of this study were: the responses of the study's sample to the survey (25 questions), were all positive, except for the questions $(4,6,7,8,9,10$, $13,20)$ as the means for these questions were less than three (midpoint $=3$ ) relative to the mean. As for the one sample T-test analysis, all questions exceeded 1.96.

The study results indicated that the Jordanian population in Amman has adequate information regarding the risks associated with the use of Analgesics, as the question twenty three (understand the medical instructions of analgesics.) was ranked first among the questions with an average mean (3.7733) and t-value (49.420).

The members of the sample check the information they have before sharing it with others with an average mean (3.7267) and (41.783) t-value, this indicates that they aware of their responsibility among sharing medical information.

As for the hypothesis of the study, the first hypothesis (There is an effect of the awareness regarding the proper use on the awareness of the Jordanian population in Amman regarding the risks associated with the use of

\section{REFERENCES}

1. Stosic R, Dunagan F, Palmer H, Fowler T, Adams I. Responsible self-medication: perceived risks and benefits of over-the-counter analgesic use. International Journal of Pharmacy Practice. 2011 Aug 1;19(4):236-45.

2. Moore RA, Wiffen PJ, Derry S, Maguire T, Roy YM, Tyrrell L. Non-prescription (OTC) oral analgesics for acute pain-an overview of Cochrane reviews. Cochrane Database of Systematic Reviews. 2015(11).

3. Roumie CL, Griffin MR. Over-the-counter analgesics in older adults. Drugs \& aging. 2004 Jul 1;21(8):485-98.

4. Chiam E, Weinberg L, Bellomo R. Paracetamol: a review with specific focus on the haemodynamic effects of intravenous administration. Heart, lung and vessels. 2015;7(2):121.

5. Mallet C, Eschalier A, Daulhac L. Paracetamol: Update on its Analgesic Mechanism of Action. InPain Relief-From Analgesics to Alternative Therapies 2017. InTech.

6. Cashman JN. The mechanisms of action of NSAIDs in analgesia. Drugs. 1996 Nov 1;52(5):13-23.

7. Sangha S, Oviedo JA. Over-the-counter nonsteroidal antiinflammatory drugs and risk of gastrointestinal symptoms. The American journal of gastroenterology. 2003 May;98(5):1203.

8. Busson M. Update on ibuprofen. Journal of International Medical Research. 1986 Mar;14(2):53-62.

9. Fendrick AM, Pan DE, Johnson GE. OTC analgesics and drug interactions: clinical implications. Osteopathic medicine and primary care. $2008 \mathrm{Dec} ; 2(1): 2$. analgesics.) was accepted with a value of one sample Ttest analysis of 75.148, which exceeded 1.96 and this indicates that the knowledge about the proper use of analgesics plays an important role in people awareness about the risks associated with analgesics usage, and with a mean of 2.76444 members of the sample admitted that they do not have enough information about the proper use. Therefore, strengthening communities' awareness on analgesics usage and integrated efforts of individuals, communities, and health facilities are highly necessary. The second hypothesis (There is an effect of the Trust in information provided by other people about Analgesics on the awareness of the Jordanian population in Amman regarding the risks associated with the use of analgesics.) was also accepted with a t-value of 73.754, which shows an important role in individuals awareness of analgesics, health facilities should aware population to not share the information unless they are provided by health care team. The third hypothesis (There is an effect of the Knowledge of side effects of Analgesics on the awareness of the Jordanian population in Amman regarding the risks associated with the use of analgesics) was accept with a tvalue of 55.580 and showed the strongest correlation and influence in the awareness with pearson's correlation of .419 , this indicates that the awareness about side effects of analgesics plays an active and most important role in the awareness of the risks associated with the analgesics usage. The fourth hypothesis with a $64.049 \mathrm{t}$-value was accepted. As a result we reject the null hypothesis (People don't have enough awareness about the risks associated with the use of analgesics) and accepted the alternative hypothesis. Strengthening communities' awareness on analgesics usage and integrated efforts of individuals, communities, and health facilities are highly necessary to assure and increase the populations' knowledge about analgesics. Further studies on larger sample size have to be done.

10. Abbott FV, Fraser MI. Use and abuse of over-the-counter analgesic agents. Journal of Psychiatry and Neuroscience. 1998 Jan;23(1):13.

11. Lefterova A, Getov I. Study on Consumers' References and Habits for Over-the-counter Analgesics Use. Central European journal of public health. 2004 Mar;12(1):43-5.

12. Seeman TE. Health promoting effects of friends and family on health outcomes in older adults. American Journal of Health Promotion. 2000 Jul;14(6):362-70.

13. Kassie AD, Bifftu BB, Mekonnen HS. Self-medication practice and associated factors among adult household members in Meket district, Northeast Ethiopia, 2017. BMC Pharmacology and Toxicology. 2018 Dec;19(1):15.

14. Kumar R, Goyal A, Padhy BM, Gupta YK. Self-medication practice and factors influencing it among medical and paramedical students in India: A two-period comparative crosssectional study. Journal of natural science, biology, and medicine. $2016 \mathrm{Jul} ; 7(2): 143$.

15. Lukovic JA, Miletic V, Pekmezovic T, Trajkovic G, Ratkovic N, Aleksic D, Grgurevic A. Self-medication practices and risk factors for self-medication among medical students in Belgrade, Serbia. PloS one. 2014 Dec 11;9(12):e114644.

16. Palos GR, Mendoza TR, Cantor SB, Aday LA, Cleeland CS. Perceptions of analgesic use and side effects: what the public values in pain management. Journal of pain and symptom management. 2004 Nov 1;28(5):460-73.

17. Sultana M. A Survey on knowledge and attitude about analgesic use, its indication and side effects (Doctoral dissertation, East West University). 
18. Wood DM, English E, Butt S, Ovaska H, Garnham F, Dargan PI. Patient knowledge of the paracetamol content of over-thecounter (OTC) analgesics, cough/cold remedies and prescription medications. Emergency Medicine Journal. 2010 Jan 1:emj2010

19. Brown-Johnson CG, Boeckman LM, White AH, Burbank AD, Paulson S, Beebe LA. Trust in Health Information Sources: Survey Analysis of Variation by Sociodemographic and Tobacco Use Status in Oklahoma. JMIR public health and surveillance. 2018 Jan;4(1).

20. Chen K. Public Awareness and Information Sources of Health Publicity for Three Major Infectious Diseases in Rural Zhejiang Province, China. InINTERNATIONAL Journal of Epidemiology 2015 Jan 1 (Vol. 44, Pp. 168-168). Great Clarendon St, Oxford Ox2 6dp, England: Oxford Univ Press.

21. Mertens F, Távora R, Nakano EY, Castilhos ZC. Information sources, awareness and preventive health behaviors in a population at risk of Arsenic exposure: The role of gender and social networks. PloS one. 2017 Oct 9;12(10):e0186130.

22. Huston SA, Jackowski RM, Kirking DM. Women's trust in and use of information sources in the treatment of menopausal symptoms. Women's Health Issues. 2009 Mar 1;19(2):144-53.

23. Brounéus F, Macleod G, Maclennan K, Parkin L, Paul C. Drug safety awareness in New Zealand: public knowledge and preferred sources for information. Journal of primary health care. 2012;4(4):288-93.

24. Alsamydai Am. the opinions of pharmacists about the possibility of using electronic means of communication by pharmaceutical companies to facilitate the process of trade exchange.

25. Alsamydai Am, Baqer Ab. measuring patient satisfaction regarding the quality of healthcare service provided by pharmacists. 